\title{
Retrospective Evaluation of the Anaesthetic Method Used in Caesarean Sections
}

\author{
Gökcen BAŞARANOĞLU1', Metin BAŞARANOĞLU² \\ ${ }^{1}$ Department of Anesthesiology and Reanimation, Bezmialem Vakif University Faculty of Medicine, Istanbul, Turkey \\ ${ }^{2}$ Department of Internal Medicine Gastroenterology, Bezmialem Vakif University Faculty of Medicine, Istanbul, Turkey
}

\section{ABSTRACT}

Objective: The goal of this study was to evaluate the anaesthetic method used in patients who have undergone caesarean section.

Methods: The anaesthetic reports that belong to the women who underwent caesarean section between the years 2014 and 2015 were evaluated in terms of the demographic data, anaesthetic methods, and reported complications.

Results: Although 299 patients received general anaesthesia, 75 patients received regional anaesthesia during caesarean section. Mortality was not observed in any patient.

Conclusion: Although regional anaesthesia is currently being used mostly in many countries for caesarean sections, our patients chose the general anaesthesia. Making the method of anaesthesia depend on patients' preferences with the exception of some special conditions such as patients' fear and anesthesiologist's additional aliments might have a role in this circumstance.

Keywords: Regional, general, anesthesia, obstetrics, intubation

\section{Introduction}

Caesarean sections are important operations in terms of anesthesia, and the frequency of difficult intubation during general anesthesia is 8-fold higher than that in normal population because of physiological changes caused by pregnancy. In obstetric anesthesia, regional anesthesia is preferred because of the distinctive state of pregnancy, unless there is a contraindication. However, the desire of the patient should also be considered. In this study, the anesthesia techniques used for caesarean sections were investigated.

\section{Methods}

After receiving permission from the General Coordinator of our hospital, the anesthesia records of women who underwent caesarean sections between April 2015 and April 2014 were examined retrospectively. The files of patients were evaluated with respect to age, weight, American Society of Anesthesiologists (ASA) class, and postoperative complications.

\section{Statistical analysis}

The data were evaluated using the Student's t-test and presented as mean \pm standard deviation. The value of $\mathrm{p}<0.05$ was accepted to be statistically significant.

\section{Results}

The demographic data of patients are presented in Table 1. Of the patients, 75 underwent regional anesthesia and 299 underwent general anesthesia. It was found that patients with a high ASA class and risky pregnancy (placenta previa, placenta percreta, having a history of more than three caesarean sections, etc.) were operated under general anesthesia. No mortality was observed in any patient.

Address for Correspondence: Gökcen Başaranoğlu; Department of Anesthesiology and Reanimation, Bezmialem Vakif University Faculty of Medicine, Istanbul, Turkey .Phone: +90 5325899871 E-mail: gbasaranoglu@hotmail.com 


\section{Discussion}

At present, regional anesthesia is preferred instead of general anesthesia because of some reasons, including the distinctive state of pregnancy, an increase in difficult intubation processes during general anesthesia, immediate establishment of a relationship between mother and baby with regional anesthesia, and the baby being less affected by an anesthetic agent $(1,2)$. At our hospital, the choice of the anesthesia technique for caesarean sections is made by the patient, obstetrician, and anesthetist together. If there is no contraindication determined by the anesthetist and obstetrician, the choice of the patient could be considered. Each parturient coming for a caesarean section is informed about the anesthesia techniques approximately $5 \mathrm{~min}$ before being placed onto the operation table, unless there is an emergency case. It is explained that, with regional anesthesia, the baby will be less affected by the anesthetic agent, the mother will be able to proceed with the process of labor and see the baby just after birth, and even, she can kiss the baby if she does not have any infectious disease and if the baby is healthy. Moreover, it is explained that she will not experience any pain during regional anesthesia. Patients are also informed about possible complications, including nausea, vomiting, postoperative headache, and backache, and about the methods to cope with these complications. The use of this technique is up to the patient's choice. Most of the patients do not prefer regional anesthesia because of their previous experiences or the experiences of their family members and friends or their internet search. According to the results of our study, the rate of choosing regional anesthesia is lower than that of choosing general anesthesia. This might have resulted from patients' fears such as injection, remaining paralyzed, experiencing pain during surgery, and having a headache after caesarean section. In our previous study on labor analgesia in patients visiting our outpatient clinic, 17\% of patients did not prefer regional analgesia because they were afraid of (3). Regional anesthesia can be used safely by experienced specialists in compatible patients.

Studies have revealed that complications associated with general anesthesia are more frequent than those associated with regional anesthesia. In the administration of general anesthesia, difficult intubation related to anesthesia, esophageal intubation, aspiration, insufficient ventilation and respiratory problems, and more suppressed immune system can be observed $(4,5)$. On the other hand, regional anesthesia can pose some risks such as local anesthetic toxicity, high spinal block, subdural hematoma, and headache. In patients who will undergo a caesarean section, the preferred anesthesia technique for surgery is regional anesthesia, i.e., spinal or combined spinal epidural anesthesia, unless there is an emergency situation and if the patient wants.

In the United Kingdom, maternal deaths are regularly recorded. All reasons for maternal deaths are listed in these recordings, and the reasons for anesthesia-induced deaths are specified. According to MBRRACE (Mothers and Babies: Reducing Risk through Audits and Confidential Enquiries) in December 2014, although the maternal death rate was $11 / 100,000$ between 2006 and 2008, it decreased to $10 / 100,000$ between 2010 and 2012. Of these deaths, $2 / 3$ was associated with medical and mental health problems, but $1 / 3$ resulted from problems directly related to pregnancy such as bleeding (6). In our country, inspections are not made in detail as in the United Kingdom. The number of maternal deaths associated with anesthesia is unknown. According to the Turkey National Maternal Mortality Study (2005) results, the incidence of maternal mortality is 28.5 mothers per 100,000 live births. Unfortunately, the reason could not be determined in $10 \%$ of maternal deaths. The number of deaths associated with anesthesia is unknown. In our hospital, an anesthetist and an obstetrician are available for $24 \mathrm{~h}$, and cesarean sections are actively performed by specialists. The reason for the non-occurrence of mortality can be explained by the obstetric team works in cooperation with anesthetists and intensive care givers. The reasons for maternal mortality in our country are presented in Table 2 (7).

Although the frequency of regional anesthesia is gradually increasing in America and Europe, regional anesthesia is preferred more commonly in some countries, and general anesthesia is preferred more commonly in others $(8,9)$. Mothers choosing general anesthesia in these studies preferred it because of their fears of injection, pain, and headache. In studies conducted in our country, the choice of general anesthesia differs in university and state hospitals. For instance, although the rate of regional anesthesia administration in caesarean sections was found to be $77 \%$ in some university hospitals, it was approximately $30 \%$ in others (10). According to our results, the rate of regional anesthesia choice is $25 \%$, which is similar to the mean rate across Turkey. Difficult intubation during

\section{Table 1. Demographic data of patients}

\begin{tabular}{|l|c|c|}
\hline & General anesthesia & Regional anesthesia \\
\hline Age (years) & $30.65 \pm 5.22$ & $30.79 \pm 4.89$ \\
\hline Weight $(\mathrm{kg})$ & $78.99 \pm 13.22$ & $79.98 \pm 14.53$ \\
\hline
\end{tabular}

Table 2. Causes of maternal mortality in our country

Ante-, intra-, and post-partum hemorrhage $24.9 \%$

Other direct reasons

(embolism, surgical complications, uterus rupture)

Edema, proteinuria, and hypertensive disorders

$18.4 \%$

Infections associated with pregnancy

$15.7 \%$

Suicide

$4.6 \%$

$3.2 \%$

Unknown direct reasons

$21.2 \%$

Deaths in early pregnancy

$1.8 \%$ 
general anesthesia and local anesthetic toxicity associated with regional anesthesia was not observed in our patients. Headache was observed only in 1 of 75 patients, and her headache was healed with caffeinated drinks and analgesics without requiring epidural blood patch treatment.

\section{Conclusion}

In conclusion, in our hospital, regional anesthesia is administered in caesarean sections, but regional administrations have fallen behind general anesthesia because of the preferences of patients. However, no change has been observed in the maternal-infant mortality rate. The use of regional anesthesia in caesarean sections can be increased by providing formal and non-formal education to pregnant women.

Ethics Committee Approval: Ethics committee approval was obtained.

Informed Consent: Due to the retrospective nature of this study, informed consent was waived.

Peer-review: Externally peer-reviewed.

Author Contributions: Concept - G.B.; Design - M.B.; Supervision - G.B.; Funding - M.B.; Materials - M.B.; Data Collection and/or Processing - G.B.; Analysis and/or Interpretation - G.B.; Literature Review - M.B.; Writer G.B.; Critical Review - M.B.

Conflict of Interest: The authors declared no conflict of interest.

Financial Disclosure: The authors declared that this study has received no financial support.

\section{References}

1. Lai HY, Tsai PS, Fan YC, Huang CJ. Anesthetic practice for Caesarean section and factors influencing anesthesiologists' choice of anesthesia: a population-based study. Acta Anaesthesiol Scand 2014; 58: 843-50. [CrossRef]

2. Jenkins JG, Khan MM. Anaesthesia for Caesarean section: a survey in a UK region from 1992 to 2002. Anaesthesia 2003; 58: 1114-8. [CrossRef]

3. Başaranoglu G, Idin K, Batmaz G, Topuz U, Uysal H, Salihoglu Z. The attitudes and behaviors of pregnanat women about labor anesthesia. Bezmialem Science 2014; 2: 65-70. [CrossRef]

4. Chen YH, Rau RH, Keller JJ, Lin HC. Possible effects of anaesthetic management on the $1 \mathrm{yr}$ followed-up risk of herpes zoster after Caesarean deliveries. Br J Anaesth 2012; 108: 278-82. [CrossRef]

5. Rukewe A, Fatiregun A, Adebayo K. Anaesthesia for caesarean deliveries and maternal complications in a Nigerian teaching hospital. Afr J Med Med Sci 2014; 43: 5-10.

6. MBRRACE Mothers and Babies: Reducing Risk through Audits and Confidential Enquiries. Available at: https://www.npeu.ox.ac.uk/downloads/files/mbrrace-uk/reports/Saving\%20Lives\%20Improving\%20 Mothers\%20Care\%20report\%202014\%20Exec\%20Summary.pdf.

7. Türkiye Ulusal Anne Ölümleri Çalışması 2005. Available at: http:// www.hips.hacettepe.edu.tr/uaop_ankara/ozet_rapor.pdf

8. Fassoulaki A, Staikou C, Melemeni A, Kottis G, Petropoulos G. Anaesthesia preference, neuraxial vs general, and outcome after caesarean section. J Obstet Gynaecol 2010; 30: 818-21. [CrossRef]

9. Ahmad I, Afshan G. Knowledge and attitudes of Pakistani women towards anaesthesia techniques for caesarean section. J Pak Med Assoc 2011; 61: 359-62.

10. Kocamanoğlu IS, Sarihasan B, Şener B, Tur A, Şahinoğlu H, Sunter T. Methods and complications of anesthesia in cesarean/section operations: retrospective evaluations of 3552 cases. Turkiye klinikleri j med sci 2005; 25: 810-6. 